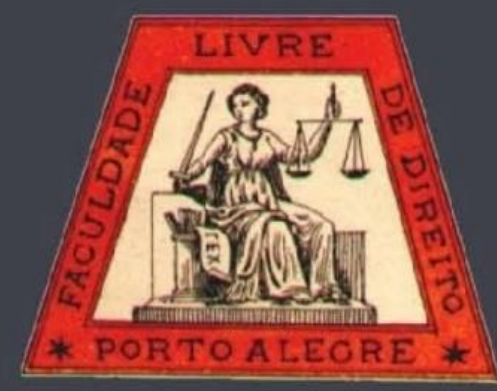

\title{
As dificuldades da implementação do federalismo social na república brasileira
}

The difficulties of implementing the social federalism in the Brazilian Republic

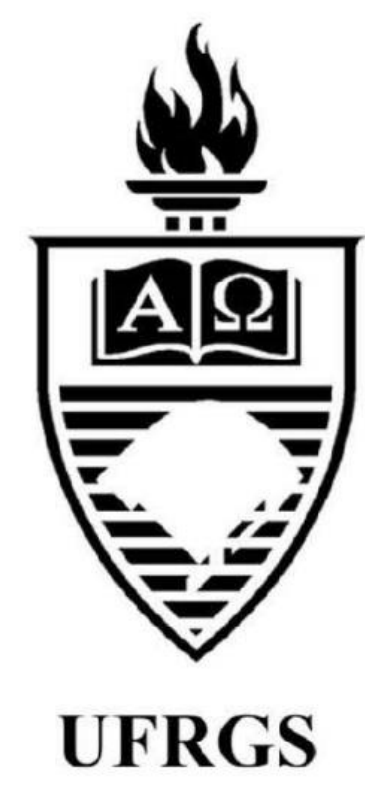

Rosendo Freitas de Amorim Universidade de Fortaleza

Francisco Jório Bezerra Martins

Universidade de Fortaleza 


\title{
As dificuldades da implementação do federalismo social na república brasileira
}

\author{
The difficulties of implementing the social federalism in the Brazilian Republic
}

Rosendo Freitas de Amorim*

Francisco Jório Bezerra Martins $^{* *}$

\begin{abstract}
REFERÊNCIA
AMORIM, Rosendo Freitas de; MARTINS, Francisco Jório Bezerra. As dificuldades da implementação do federalismo social na República brasileira. Revista da Faculdade de Direito da UFRGS, Porto Alegre, n. 37, p. 116130, dez. 2017.
\end{abstract}

\section{RESUMO}

A República Federativa do Brasil elegeu como direitos supremos a vida, educação, saúde, habitação, dentre outros. A consecução de tais direitos exige um esforço da República para, harmonizando as competências dos entes políticos da federação, delinear a atividade de cada um deles na implementação das políticas públicas. Para além de amoldar as ações públicas para a consecução desse fim, exige-se de igual sorte que especialmente o Distrito Federal, os Municípios e os Estados tenham condições financeiras suficientes para mantê-los. No entanto, percebe-se que o nosso federalismo privilegia a União, permitindo-lhe a maior possibilidade de arrecadação, enquanto os demais contratantes do pacto federativo ficam à espera de repasses federais. Desta forma, o federalismo social cooperativo necessita de ajustes para aperfeiçoar as atribuições, bem como operar uma melhor arrecadação a fim de dar efetividade aos direitos e garantias fundamentais, bem como aos direitos sociais.

\section{PALAVRAS-CHAVE}

Federalismo social. Receita tributária. Políticas Públicas. Implementação.

\section{ABSTRACT}

The Federative Republic of Brazil has elected as supreme rights life, education, health, housing, among others. The achievement of these rights requires an effort by the Republic to harmonize the competences of the political entities of the federation, to delineate the activity of each of them in the implementation of public policies. In addition to tailoring public actions to achieve this goal, it is equally necessary that the Federal District, the Municipalities and the States have sufficient financial conditions to maintain them. However, we perceive that our federalism privileges the Union, allowing it the greater possibility of tax collection, while the other contractors of the federative pact wait for federal transfers. In this way, cooperative social federalism needs adjustments to improve the attributions, as well as to operate a better tax collection in order to give effect to the fundamental rights and guarantees, as well as to social rights.

\section{KEYWORDS}

Social federalism. Tax revenue. Public policy. Implementation.

\section{SUMÁRIO}

Introdução. 1. Aspectos históricos da descentralização e a origem do federalismo brasileiro. 2. A Constituição de 1988 e o federalismo social. 3. As dificuldades tributárias de implementar um federalismo social democrático. Conclusão. Referências.

\footnotetext{
* Doutor em Sociologia pela Universidade Federal do Ceará (UFC). Professor titular da Universidade de Fortaleza (UNIFOR). Professor Colaborador do Programa de Pós-Graduação em Direito da Universidade de Fortaleza (UNIFOR).

** Doutorando em Direito Constitucional pelo Programa de Pós-Graduação em Direito da Universidade de Fortaleza (UNIFOR). Professor do curso de Direito da Universidade de Fortaleza (UNIFOR).
} 


\section{INTRODUÇÃO}

A Federação é composta por um conjunto, congregação ou aliança de Estadosmembros, dotados de autonomia política e administrativa. Por sua vez, a União Federal, através do Chefe do Executivo, exerce a soberania em nome do todo federativo.

Trata-se de uma sociedade de Estados, onde existe uma pluralidade de legislação e administração de cada unidade autônoma, sendo estas respeitantes dos princípios e regras gerais estabelecidas na Constituição da Federação. Cada Estado-membro promulga sua própria Constituição Estadual, elege seus dirigentes e também os integrantes da sua respectiva Casa legislativa.

Cumpre apenas esclarecer que no caso brasileiro, desde 1988 os Municípios foram alçados a condição de integrantes do pacto federativo. Isto comporta registrar que sob o ponto de vista jurídico material, está em pé de igualdade com a União e os Estados.

Observa-se, portanto, que o fim perseguido pelo estabelecimento da forma federativa é o de descentralizar a administração. A descentralização promovida pela federação é a de cunho administrativo e política. Com isso, administrativamente implica afirmar da subtração de competências de um centro, transferindo-as aos entes periféricos; e, politicamente, a capacidade de criar norma legal sobre matéria de sua responsabilidade, ensejando uma verdadeira coabitação de micro sistemas jurídicos orquestrados por uma Constituição Federal rígida.

O princípio federativo cristaliza o conceito de uma forma de descentralização do poder estatal no âmbito de seu território, buscando uma harmonia na coexistência de várias ordens jurídicas parciais com uma ordem jurídica central.

As relações entre os Estados-membros e o governo central evidenciam que o federalismo foi ditado por razões práticas, notadamente com a convivência harmoniosa e pacífica de aglomerações sócio-políticas presentes em um mesmo território. Essas aglomerações tinham em vista a participação igualitária no processo decisório do governo, mas na qualidade de Estados-membros, abriam mão da soberania 'local' em prol da formação do todo político, da soberania unificadora.

Pinto Ferreira (1983, p. 909) trouxe à baila uma conceituação de federalismo que, apesar de anterior à nossa Carta que erigiu os Municípios a iguais entes federados, vale a pena colacionar, diz o autor:

\begin{abstract}
O Estado Federal é uma organização, formada sobre a base de uma repartição de competências entre o governo nacional e os governos estaduais, de sorte que a União tenha a supremacia sobre os Estados-Membros e estes sejam entidades dotadas de autonomia constitucional perante a mesma União.
\end{abstract}

José Tavares (1996, p. 19), por sua vez, adverte para a inexistência de um conceito unívoco de federalismo, sendo "uma realidade variável no espaço, no tempo e em grau", "sendo, nalguns casos, associados, total ou parcialmente, a realidades afins, tais como descentralização, Estado unitário regional, integração e outras".

O federalismo é uma espécie de descentralização política ao fragmentar ou reconhecer a divisão de um território em coletividades territoriais dotadas de autonomia política, mas desprovidas de soberania, que é entregue à união dos Estados.

A complexidade de um Estado federal exige especial atenção por parte do legislador constituinte, face à necessidade de organizar o poder político nacional. No momento inicial há que repartir as atribuições (e correspondentes poderes) entre a União e os Estados federados; em segundo lugar, tem de proceder-se à 
atribuição de poderes aos órgãos criados em cada um daqueles níveis (união e Estados federados).

$\mathrm{Na}$ estrutura federal brasileira convivem harmoniosamente a União federal, os Estadosmembros, o Distrito federal e os Municípios. A repartição de competência entre os componentes da federação fulmina a errônea tese de que há hierarquia entre o governo central e os governos locais. Cada unidade possui atribuição própria e exclusiva, representantes eleitos dentre os seus comuns, orçamento e pessoal próprio, tudo determinado pelo mandamento constitucional.

Ao examinar nosso texto constitucional, percebe-se que foi adotado o federalismo cooperativo. Busca-se uma interação entre as esferas federal, estadual e municipal, no sentido de colaborar em conjunto para a perseguição dos vários fins do Estado, seja na prestação de serviços, na assistência técnica ou até mesmo na cooperação financeira para a execução de obras e projetos.

Para que esta cooperação se efetive, a União, os Estados-membros e os Municípios desenvolvem mecanismos de integração e cooperação governamental recíprocos.

No desenvolvimento deste ensaio, buscar-se-á demonstrar que a cooperação delineada em nossa Constituição carece ainda de vários ajustes. Da forma como hoje ela está materializada, apenas evidencia a robustez da União, que aqui e acolá é forçada a transferir recursos aos Estados e Municípios com a finalidade de alcançar desideratos sociais.

Visto por esse prisma, defende-se a necessidade de uma melhor delineação constitucional das competências e atribuições sociais dos Estados, Distrito Federal e Municípios, bem como sejam os mesmos agraciados com recursos próprios para adimplir e manter tais obrigações.

\section{ASPECTOS HISTÓRICOS DA DESCENTRALIZAÇÃO E A ORIGEM DO FEDERALISMO BRASILEIRO}

O período imperial brasileiro foi marcado pelo unitarismo e forte centralização política. Essa exagerada concentração de poder nas mãos do Imperador foi cedendo de forma gradual, tanto face às necessidades de empreender um melhor governo, bem como as exigências e revoltas populares clamando por alguma autonomia. A Constituição de 1824, já vislumbrando o ideal federalista, buscou corresponder ligeiramente a essa expectativa, sem, contudo, perder o controle das Províncias.

No ano de 1834, foi editada a Lei de 12 de agosto de 1834, conhecida como 'Ato Adicional', que veio a oferecer ainda mais substrato político para fomentar a luta pelo federalismo. Citado ato cerceou a autonomia municipal, esvaziando sua competência de autogoverno, transformado o Município em um mero executor dos ditames provinciais, ao mesmo passo em que ampliou a competência das Províncias, que passaram a dispor quase da totalidade da gerência dos negócios municipais. Essa mudança de política desagradou os chefes do símbolo da povoação e organização administrativa, ou seja, os gestores públicos municipais. No afã de oferecer respostas aos federalistas, D. Pedro II promoveu uma descentralização excessiva e desorganizada, como nos dizeres de Vamireh Chacon (1976, p. 115) "à revelia e em prejuízo das populações vivendo em comunidades reais, os municípios, e não em abstratos Estados".

O federalismo brasileiro foi inaugurado pelo Decreto n. ${ }^{\circ} 1$ de 15 de 11.1889 , em resposta ao regime centralizador adotado pela monarquia. A principal ideia da federação era conferir aos Estados, antes denominados Províncias, autonomia, bem como incentivar a descentralização no território, de dimensão 
continental. O impulso federalista foi tão açodado que o Decreto, fruto das paixões políticas, conferia aos Estados a garantia de exercício de sua legítima "soberania", uma impropriedade que veio a ser suprimida na primeira Carta Republicana de 1891.

A adoção do federalismo representa uma das mais importantes contribuições para decidir o problema da descentralização, vindo a ser rapidamente assimilado na política nacional por parecer ideal face às diversidades geográficas, econômicas e sociais existentes à época.

Em 1891, a primeira Constituição republicana, inspirada na Constituição norteamericana, estabelecia o federalismo e o presidencialismo como princípios norteadores do regime republicano. A Igreja foi desvinculada do Estado e estabeleceram-se eleições diretas para Presidente, Governadores, Senadores, Deputados estaduais e federais.

Rui Barbosa ${ }^{1}$ já vislumbrava o perigo que rondava o país, quando da implantação do federalismo num Estado marcado pela desigualdade regional. Seu discurso proferido em 29.01.1891 na Assembleia Constituinte pontificou que:

[...] os Estados grandes disputarão entre si a gestão de negócios públicos, e os Estados pequenos, arrastando uma vida inglória $\mathrm{e}$ obscura, não hão de ter a mínima interferência nos negócios de nossa pátria, hão de ser sempre esmagados pela enorme superioridade com que os outros dotam a Constituição do país

A Constituição de 1934 foi inovadora ao inaugurar o federalismo tridimensional brasileiro, estabelecendo a divisão de competência tripartida entre a União, os Estados e os Municípios. Até 1934, as competências da

${ }^{1}$ BRASIL. Ministério da Educação e Cultura. "O art. 6. ${ }^{\circ}$ da Constituição e a intervenção de 1920 na Bahia". Obras completas de Rui Barbosa. Rio de Janeiro: Fundação Casa de Rui Barbosa, v. XLVII, t. IV, 1920, p. 112.
União e dos Estados-membros eram radicalmente separadas. Existia à época o federalismo dualista ou clássico, cuja característica principal era a repartição horizontal de competências, cabendo a União e aos Estados parcela delimitada de competências reservadas. Esclareça-se apenas que o Município ainda não fazia parte ad federação.

A vigência da Constituição de 1934 foi muito curta, e três anos depois, em 1937, já vigorava outra Carta Política que fortaleceu ainda mais os poderes da União. A nova Constituição foi fruto de um golpe por Getúlio Vargas, que após dissolver o Congresso Nacional implantou o denominado Estado Novo, sepultando o novel federalismo cooperativo.

A Constituição de 1946 restabeleceu a Federação no seu sentido real. Inspirada em ideais norte-americanos (mantinha o título de Constituição dos Estados Unidos do Brasil), franceses e alemães, foi tida como uma das mais importantes, porque buscava a harmonização entre a classe proletária que insistia na participação, e a burguesa conservadora. No entanto, no que tange à federalização, os avanços foram ínfimos.

Os militares insatisfeitos com a política populista adotada e o descontrole econômico que gerou inflação desenfreada em 1964, decidiram assumir o poder. Escudados no argumento de reestruturação do governo e desenvolvimento, promoveram o fortalecimento do Poder Executivo tomando à força o poder.

A Constituição de 1946 deu lugar a de 1967, na qual a arbitrariedade imperava. O federalismo ruía ante a impotência do Judiciário e a legalidade estava suspensa para aqueles que insistiam em combater o governo da época.

A crise política e econômica seguia a passos largos e a última manobra se concretizou pelo Ato Institucional n. ${ }^{\circ}$ 5, maior instrumento de centralização, conferindo ao Presidente poderes quase que ilimitados. 
O fim do regime militar foi marcado pela Constituição de 1988. Na tentativa de afastar-se dos moldes centralistas das anteriores, conferiu mais recursos, especialmente no âmbito tributário, aos Estados e Municípios, posto que sem numerário para fazer valer o autogoverno, falece a autonomia e o alcance dos objetivos sociais. A maior relevância a nível políticoadministrativo organizacional, foi o erigir $\mathrm{o}$ Município à qualidade de ente da Federação.

De toda essa exposição, registra-se que os idos de 1937 a 1945, bem como de 1964 a 1984, foram os períodos mais tenebrosos da federação, intervalos nos quais Estados e Municípios, sob o ponto de vista político, eram tratados como meras porções administrativas territoriais do poder central, cujos governantes, eram escolhidos pelo Presidente da República.

\section{A CONSTITUIÇÃO DE 1988 E FEDERALISMO SOCIAL}

O federalismo cooperativo praticado hoje no Brasil é operado com base na divisão de competências, na qual a União, os Estadosmembros, os Municípios e o Distrito Federal além de possuírem possuem das competências exclusivas, possuem, também, competências comuns em áreas como social e política, saúde, habitação e educação.

Sem dúvida o modelo cooperativo apresenta vantagens, como por exemplo, a possibilidade de outro componente do Estado federado realizar uma tarefa necessária e pontual à um determinado segmento ou coletividade, atividade essa que não seja de competência exclusiva atribuição de outrem. Esse fato também gera a obrigação de conduzir as partes a um entendimento no momento de realizar a obra ou prestar o serviço público, favorecendo as relações intergovernamentais.

No entanto, a cooperação apresenta alguns inconvenientes, notadamente quando a interdependência entre diversas pessoas gera uma política de morosidade, em que "um fica esperando pelo outro", ou, nos dizeres de Reinhold Zippellius (1997, p. 513):

[...] as práticas de cooperação, em sentido
restrito, trazem consigo também desvantagens,
afigurando-se complicadas e muitas vezes
dispendiosas. Transportam o risco de que uma
política de 'vistas largas' seja substituída por
uma 'política do denominador comum', pouco
eficiente" para demonstrar que os acordos
celebrados entre os entes federados 'conduzem
frequientemente a que a conciliação entre pontos
de vista defendidos pelas diversas entidades
envolvidas seja assumida pelas burocracias
especializadas [...]'.

Infelizmente, a burocracia e demais características apontadas pelo professor supramencionado, leva igualmente a uma redução da transparência da administração pública.

Tanto assim é que a Constituição Federal é imprecisa ao decidir quem deveria ter o compromisso primário de atuar em certos setores, tais como proteção do meio ambiente, saúde, combate à fome e pobreza, incentivos à educação, ciência, cultura, habitação e saneamento, haja vista ser competência comum, por força do que estabelece o art. 23.

Apesar de benéfico, o federalismo cooperativo pode sim trazer consigo alguns inconvenientes. Quando se aborda o tema cooperação, não se pode perder de vista que a cooperação deve ser um fím almejado pelos atores do pacto federativo. Instituí-la como maneira a diminuir as diferenças entre a União e os Estados, mostra, quase sempre, que há um privilégio daquela relativamente aos demais entes políticos da federação. Assim, caso os ditames constitucionais tratassem de forma equânime os celebrantes da federação, a cooperação dar-se-ia a nível infraconstitucional, e não por uma imposição.

A respeito desse raciocínio, Paulo 
Bonavides (1996, p. 434), o denominou de "federalismo cooperativo autoritário". O autor o considera:

[...] de índole centralizadora e compressiva das autonomias estaduais, vulnera o princípio democrático e ignora as casas do congresso e as Assembléias dos Estados-Membros como instituições do poder, com as quais o cidadão mais de perto se sente identificado e sobre as quais deposita a mais alta parcela de confiança.

Desta forma, defende Paulo Bonavides o federalismo cooperativo democrático, no qual esteja presente a participação popular, e não apenas as determinações oriundas das camadas políticas instituídas, mas a participação da massa em seu desenvolvimento e aplicação.

A federação adotada no Brasil é tridimensional, e o critério utilizado para se adaptar essa realidade de autonomia plena municipal, foi o de definir expressamente a competência da União e a dos Municípios, deixando residual a competência dos Estadosmembros. No entanto, os Estados não possuem apenas competência residuais, e nem a União apenas as expressas. No primeiro caso, temos a assertiva de que aos Estados-membros é atribuída competência expressa no que tange à matéria tributária; no segundo, igualmente em matéria tributária, a União é detentora de competência residual.

Por esse prisma, Pires (2013, p. 175) traz oportuna observação de que os Estados brasileiros sofreram uma asfixia. Por suas palavras:

[...] ressai do quadro institucional o nítido desprestígio dessa instância, a verdadeira incógnita da trilogia federativa. [...] A análise superficial da tramitação legislativa, no âmbito das Assembleias Estaduais, dá mostras de que, excluídos os diplomas de natureza organizativa e administrativa, pouco sobra.

Examinando a distribuição de competências operadas pelo poder constituinte originário, concluímos que a divisão foi pensada com base no princípio da predominância do interesse. A União cuida predominantemente do interesse geral da nação, os Estados-membros dos cuidarão das questões relativas ao interesse regional respectivo, e aos Municípios é reservado o interesse local. O Distrito federal, Capital federal (art. 18, $\$ 1 .^{\circ}$ da CF), por disposição expressa, acumula, as competências estaduais e municipais, segundo o mandamento do art. 22, XVII da CF. Todos os entes da federação possuem atribuições em comum, estabelecidas pelo texto constitucional (art. 23), são áreas comuns de atuação administrativa comum, cumulativa ou paralela. No entanto, a competência concorrente é prerrogativa apenas da União, dos Estados e do Distrito federal (art. 24).

Aliás, como observado por Almeida (1995, p. 90) a Constituição “[...] estipulou cerca de trinta funções concorrentes entre União, estados e municípios, boa parte delas na área social”.

Das seis grandes áreas sociais, pode-se citar: previdência e assistência social, saúde, assistência social, emprego, habitação, redução da pobreza e desigualdade social, e educação. Em todas elas há participação do governo federal, notadamente de forma exclusiva na previdência social e emprego. Nas demais, existe uma gestão participativa, que demanda especialmente a injeção de recursos federais para sua materialização.

Sob essa perspectiva, os entes subnacionais não possuem claramente a definição de seus papéis na seara social, uma vez que a competência concorrente, e por vezes comum, enseja igualmente o aporte de capitais para a sua concretização. Para além disso, há o componente político, que influencia sobremaneira o federalismo social. Como inexiste uma definição constitucional clara a respeito da distribuição de receita para os entes federativos no que tange àquelas grandes áreas, o que finalmente provoca 
é uma acirrada disputa entre Estados, a fim de sensibilizar o Executivo federal de destinar uma maior quantidade de verba para a sua localidade. O mesmo raciocínio deve ser levado em conta relativamente aos Municípios, no entanto, com influência política reduzida. Vê-se, portanto, que o modelo de descentralização operada em nossa Constituição, fomenta um processo desigual, ao promover privilégios por vezes desarrazoados, causando impactos econômicos promovidos pela política.

Uma definição que se amolda ao estudo, é trazida por André Ramos Tavares (2013, p. 245), ao registrar que:

O federalismo social significa que o modelo de organização do Estado não é imune à preocupação com os direitos fundamentais, especialmente aqueles que demandam do Estado uma atuação positiva que envolve custos operacionais, econômicos e custos de arranjo político.

O federalismo social pode ser encontrado legislativamente, em diversos pontos da Constituição. A começar pelo art. 198, tem-se o tema da saúde pública. Da forma como está traçada a interação entre os entes, a União possui a responsabilidade de financiar e formular as políticas nacionais de saúde, bem como deve coordenar as ações intergovernamentais. Utilizando-se de outros dizeres, os Estados e Municípios ficam dependentes do financiamento e políticas nacionais, que tem o Ministério da Saúde como maior autoridade nesse gerenciamento.

Já sob o aspecto da educação, o art. 208 registra que a "União, os Estados, o Distrito Federal e os Municípios organizarão em regime de colaboração seus sistemas de ensino", para posteriormente adotar o regime colaborativo no art. 211. Relativamente à responsabilidade, delineou como sendo da União o dever de organizar o sistema federal de ensino, bem como financiar as instituições federais públicas. No que tange ao ensino médio, coube tal parcela aos Estados e ao Distrito federal; enquanto os Municípios arcam com o dever de dar impulso à educação infantil e fundamental.

Para a consecução dos direitos e garantias individuais e coletivos, e assim afirmar o compromisso do Estado brasileiro com o aspecto social, é necessária uma ação propositiva, o que implica realizar um planejamento estratégico, financeiro e político.

Portanto, partindo da premissa de que a positivação de direitos comporta um comportamento proativo do Estado para que a sociedade usufrua de tais previsões, é preciso identificar, dentro do modelo federal brasileiro, qual ente irá desempenhar tal papel, se haverá participação por parte de outras entidades federativas, bem como de onde partirá o financiamento de tais efetivações.

O Sistema Tributário Nacional estabelecido em nossa Constituição, além de nortear as diretrizes no que tange aos princípios constitucionais tributários, operando como verdadeiros instrumentos de proteção do contribuinte, traz ainda a enumeração dos tributos que abastece o Estado de recursos. Em seu bojo, são encontradas as normas cuja finalidade precípua é a de instituir e arrecadar tributos de competência dos entes políticos da federação.

Cada nível de governo tem competência, isto é, tem ao mesmo tempo poder e responsabilidade para promover determinadas políticas públicas e para alcançar esse desiderato, necessitam arrecadar recursos.

Os tributos são a principal fonte de recursos para a manutenção dos governos. Segundo o art. $3^{\circ}$ do Código Tributário $\mathrm{Nacional}^{2}$ (Lei 5.172/66), entende-se por tributo toda "prestação pecuniária compulsória, em moeda ou cujo valor nela se possa exprimir, que não constitua sanção de ato ilícito, instituída em

${ }^{2}$ Doravante CTN. 
lei e cobrada mediante atividade administrativa plenamente vinculada".

Por sua vez, os tributos podem ser divididos entre impostos, taxas $\mathrm{e}$ as contribuições. A corrente majoritária dominante, conforme à luz da interpretação constitucional, considera a existência de cinco tributos no sistema tributário brasileiro, adicionando aos já citados, os empréstimos compulsórios e as contribuições especiais. Segundo o prof. Hugo de Brito Machado (2014, p. 27), essa corrente ficou conhecida como pentapartite, já sedimentada inclusive pelo Supremo Tribunal Federal $^{3}$.

É através da arrecadação promovida pelas diversas espécies tributárias, que o Estado realiza as políticas públicas, isto é, mantém os serviços públicos (saúde, educação, segurança) e faz investimentos (urbanização de vilas, calçamento, saneamento básico, habitação popular). É bem sabido que existem outras formas do Estado (lato senso) trazer recursos para o seu cofre. Como exemplo pode-se citar as alienações onerosas (aluguéis, vendas, leilões), bem como a emissão de moeda (apesar de gerar inflação) e títulos, que por sua vez provoca o endividamento, com o consequente aumento dos juros, comprometendo o resultado do produto interno bruto.

A divisão dos tributos no texto constitucional segue uma rígida delineação. Isso significa dizer que cada ente político da federação recebe a enumeração taxativa a respeito de quais tributos pode instituir e dispor.

A União os dispõe dos seguintes impostos: a) importação; b) exportação; c)

\footnotetext{
3 AI-AgR 658576/RS, Relator Ministro Ricardo Lewandowski, $1^{\mathrm{a}}$ Turma, julgamento em 27/11/2007, publicado no DJe-165 divulg 18-12-2007 public 19-122007 DJ 19-12-2007 PP-00037 ement vol-02304-13 pp02576; AI-AgR 679355/RS, Relator Ministro Ricardo Lewandowski, $1^{\mathrm{a}}$ Turma, julgamento em 27/11/2007, publicado no DJe-165 divulg 18-12-2007 public 19-122007 DJ 19-12-2007 PP-00045 ement vol-02304-20 pp04171.
}

produtos industrializados (IPI); d) renda (IR); e) propriedade territorial rural (ITR); f) operações financeiras (IOF) e h) grandes fortunas (embora ainda não criado). Por sua vez, os Estados dispõem de apenas 03 (três) a seguir enumerados: a) ICMS - imposto incidente sobre a circulação de mercadorias e sobre prestações de serviços de transporte interestadual e intermunicipal e de comunicação; b) IPVA imposto sobre a propriedade de veículos automotores; e c) ITCD - imposto sobre a transmissão causa mortis e doações. Já os Municípios igualmente usufruem de 03 (três) impostos, a saber: a) IPTU - imposto sobre a propriedade predial e territorial urbana; b) ISS imposto sobre serviços de qualquer natureza; c) ITBI - transmissão "inter vivos", a qualquer título, por ato oneroso, de bens imóveis.

Uma simples observação já leva a concluir do notório desequilíbrio no que tange à quantidade predatória de impostos de competência da União, comparativamente comparação com os Estados e Municípios. No entanto, ela fica mais evidenciada pelo fato de que os seus tributos são mais vorazes e possuem abrangência em todo o território nacional. Já os tributos Estaduais e Municipais, além de serem restritos à suas respectivas dimensões territoriais, possuem capacidade menor de gerar renda.

$\mathrm{Na}$ tentativa de amenizar essa desigualdade relativa à quantidade de tributos e o potencial arrecadatório, o texto constitucional traz um sistema de repartição de receita tributária, o que efetivamente consagra e reafirma o federalismo cooperativo, mas, por outro lado, reforça a distância que há entre os entes, no que tange à arrecadação e responsabilidades públicas.

\section{AS DIFICULDADES TRIBUTÁRIAS DE IMPLEMENTAR UM FEDERALISMO SOCIAL DEMOCRÁTICO}

A Constituição Federal, a fim de reduzir as disparidades existentes em virtude do 
quantitativo e qualitativo de arrecadação tributária, bem como buscando amparar Estados e Municípios relativamente às suas responsabilidades sociais, promove a repartição de receita tributária. Essa repartição é simplesmente o estabelecimento de um repasse forçado aos demais entes federativos, resultado da arrecadação que não lhes é própria.

$\mathrm{O}$ art. $153, \S 5^{\circ}$, I e II contemplam os Estados e Municípios, respectivamente com 30 e $70 \%$ do imposto sobre operação financeira, isto quando o ouro for definido como ativo financeiro.

O produto da arrecadação do imposto de renda (de competência da União) será 100\% (cem por cento) revertido aos Estados, ao Distrito Federal e aos Municípios, sobre rendimentos pagos, a qualquer título, por eles, suas autarquias e pelas fundações que instituírem ou mantiverem. Isso, por força do estabelecido no art. 157 , I e 158, I.

Mais adiante, no art. 158, II, há a destinação aos Municípios de 50\% (cinquenta por cento) do produto da arrecadação do ITR (imposto da União), que inclusive pode chegar até $100 \%$, caso o aquele venha a se responsabilizar, via convênio com a União ${ }^{4}$, pela fiscalização e cobrança de tal tributo.

$\mathrm{O}$ art. 158, III, destina aos Municípios, $50 \%$ (cinquenta por cento) do tributo estadual IPVA, desde que o veículo necessariamente seja licenciado no território daquela municipalidade.

O derradeiro inciso do art. 158, por sua vez, força os Estados a entregarem aos Municípios $25 \%$ (vinte e cinco por cento) do produto da arrecadação do ICMS.

$\mathrm{O}$ art. 159, I, a, b, e c, destina $49 \%$ (quarenta e nove por cento) do produto da arrecadação dos impostos sobre renda $\mathrm{e}$ proventos de qualquer natureza e sobre produtos industrializados, da seguinte forma: a) $21,5 \%$

\footnotetext{
${ }^{4}$ A Instrução Normativa n. 884 , de 05 de novembro de
} 2008, no DOU de 06/11/2008, p. 23. (vinte e um vírgula cinco por cento) ao Fundo de Participação dos Estados e do Distrito Federal; $22,5 \%$ (vinte e dois vírgula cinco por cento) ao Fundo de Participação dos Municípios; e 3\% (três por cento) para a aplicação em programas de financiamento ao setor produtivo das Regiões Norte, Nordeste e Centro Oeste.

Estampado no art. 159, II, os Estados e o Distrito Federal são agraciados com 10\% (dez por cento) do IPI, proporcionalmente ao valor das respectivas exportações de produtos industrializados, de cujo percentual será extraído $25 \%$ (vinte e cinco por cento) aos Municípios, por força do mandamento contido no parágrafo terceiro do mesmo dispositivo.

Do apresentado, já é possível elucubrar algumas conclusões que servem de supedâneo para evidenciar a problemática relativa ao sistema tributário e o federalismo social.

Em primeiro lugar, há uma nítida diferença no quantitativo de tributos, distribuídos entre os entes da federação. Por outro lado, foi preocupação do poder constituinte, estabelecer um sistema de repartição tributária que beneficie outros entes que não os detentores da competência para instituir os tributos, a serem agraciados pela via da transferência constitucional obrigatória.

Todavia, tomando como exemplo apenas a União, se ela concede isenção ${ }^{5}$ ou reduz alíquota relativamente aos seus impostos, a consequência óbvia imediata é a diminuição da arrecadação. Havendo o recrudescimento do montante arrecadado, é evidente o impacto negativo nos Estados e Municípios que recebem porcentagem do valor arrecadado. Tal atitude, provoca implicações que submetem o beneficiado pela repartição, a uma situação de extrema vulnerabilidade, o que compromete a

\footnotetext{
${ }^{5} \mathrm{~A}$ isenção (art. $150, \S 6^{\circ} \mathrm{da} \mathrm{CF} / 88$ ) é um caso de exclusão ou dispensa do crédito tributário. Ela só pode concedida após deliberação legislativa, ou seja, mediante expressa previsão legal, notadamente provocada por um motivo socioeconômico ou sociopolítico.
} 
sua autonomia e consecução de projetos públicos.

No Estado brasileiro, é comum o Governo federal adotar a prática de reduzir a alíquota do IPI, por exemplo, a fim de estimular setores específicos da indústria, como as montadoras de automóveis, ventiladores, refrigeradores, máquinas de lavar, dentre outros. No entanto, apesar de em princípio a carga tributária trazer um alívio aos contribuintes, outros entes padecem com a diminuição da arrecadação. Nesse caso específico, tanto os Estados assim como os Municípios amargam severas perdas, com impacto notável em sua autonomia e consecução de metas públicas e sociais.

Como sabido, é na municipalidade que os administrados demandam do Estado como um todo. Ali eles se locomovem, buscam educação, moradia, lazer, saúde, dentre outros preceitos sociais básicos. Partindo desse raciocínio, fica difícil imaginar que o munícipe irá demandar dos governos federal ou estadual. As suas reclamações e exigências encontram primariamente o ente local como responsável por atender as suas necessidades.

Assim, percebe-se que o federalismo cooperativo social brasileiro expõe severamente os entes subnacionais, condicionando-os fatores economicamente imprevisíveis, que podem contribuir para o emperramento ou até mesmo diminuir a implementação das ações sociais.

Essa vulnerabilidade depõe em desfavor do cooperativismo, ameaça o aspecto social do Estado e põe em cheque o conceito de autonomia que a teoria geral do federalismo impõe ao tema.

\section{CONCLUSÃO}

A ideia central ao expor o tema deste ensaio, foi demonstrar os prolegômenos do federalismo cooperativo brasileiro, até ser alcançado o federalismo social previsto no texto
Constitucional de 1988. O federalismo pressupõe que os entes são autônomos e geram as suas próprias riquezas para perseguir o bem estar social.

Registrou-se que o pacto federativo brasileiro é inovador por contemplar a municipalidade dentre os seus integrantes.

Conjugando o tema de políticas públicas sociais e o federalismo, a Constituição aponta como fundamental a proteção do meio ambiente, saúde, combate à fome, incentivos à educação, ciência, cultura, habitação e saneamento, dentre outros, como de responsabilidade de todos os celebrantes do pacto federativo.

No entanto, em virtude da imperfeita delineação a respeito das responsabilidades relativas àqueles temas, bem como a adoção cooperativa de resolução de problemas, eventualmente surgem obstáculos que perpassam pela inércia de ações proativas, até mesmo a ausência de recursos para a efetivação e continuidade de tais políticas públicas.

A inércia muitas vezes ocorre pelo fato de que um dos entes da federação aguarda a atitude um do outro, ou, como na maioria dos casos, lhe carece o quantitativo de recursos suficientes para implementar os direitos coletivos.

O Sistema Tributário Nacional, que municia União, Estados, Distrito Federal e Municípios de tributos arrecadatórios, demonstra uma nítida preferência de favorecimento à União. Os demais, além de arrecadar menos, tanto por possuírem menos tributos, bem como serem de menor amplitude, não ficam desobrigados de prestarem auxílio à população.

É preciso desenvolver mecanismos que consigam minimizar as discrepâncias entre a arrecadação da União e dos demais entes subnacionais, assim como atenuem a diminuição de receita quando da concessão de isenções ou diminuição de alíquotas de tributos que possuem 
repartição de receita. De outra sorte, a momento político econômico mais favorável, o consecução do federalismo social, ou seja, a que desprotege a sociedade, alijando-a do concretização das políticas públicas geralmente é consectário do bem comum. relegada a um segundo plano, relegada a um

\section{REFERÊNCIAS}

ALMEIDA, Maria Hermínia Tavares. Federalismo e políticas sociais. Revista brasileira de ciências sociais, São Paulo - ANPOCS, v. 10, n. 28, p. 88-108, 1995.

AMARO, Luciano. Direito tributário brasileiro. 20. ed. São Paulo: Saraiva, 2014.

ATALIBA, Geraldo. Município e constituinte. RDP, São Paulo, ano XVIII, n. 76, p. 193-196, out./dez. 1985.

ÁVILA, Humberto. Segurança jurídica. São Paulo: Malheiros, 2011.

BARACHO, José Alfredo de Oliveira. Teoria geral do federalismo. Rio de Janeiro: Forense, 1986.

BARROSO, Luís Roberto. Direito constitucional brasileiro: o problema da federação. Rio de Janeiro: Forense, 1982.

BONAVIDES, Paulo. Do velho ao nôvo federalismo. RDA, Rio de Janeiro, v. 70, p. 500-515, maio 1962.

. A constituição aberta. 2. ed. São Paulo: Malheiros, 1996.

BRASIL. Código Tributário Nacional. Brasília, 25 out. 1966. Disponível em: <http://www.planalto.gov.br/ccivil_03/leis/15172compilado.htm>. Acesso em: 02 maio 2015.

. Constituição (1988). Constituição da República Federativa do Brasil. Brasília, 05 out. 1988. Disponível em: <http://www.planalto.gov.br/ccivil_03/constituicao/constituicaocompilado.htm>. Acesso em: 02 maio 2015.

. Ministério da Educação e Cultura. O art. 6. da Constituição e a intervenção de 1920 na Bahia. Obras completas de Rui Barbosa. Rio de Janeiro: Fundação Casa de Rui Barbosa, v. XLVII, t. IV, p. 112, 1920.

COELHO, Sacha Calmon Navarro. Curso de direito tributário brasileiro. 13. ed. Rio de Janeiro: Forense, 2014.

DALLARI, Dalmo de Abreu. O Estado Federal. São Paulo: Ática, 1986.

ELALI, André. O federalismo fiscal brasileiro e o sistema tributário nacional. São Paulo: MP, 2005. 
FERREIRA, Luiz Pinto. Princípios gerais do direito constitucional moderno. 6. ed. v. II. São Paulo: Saraiva, 1983.

LEAL, Victor Nunes. Alguns problemas municipais em face da constituição In: BRASIL. Ministério da Justiça. Problemas de Direito Público. Brasília: Ministério da Justiça, v. 1. p. 312-337, 1999.

MACHADO JÚNIOR, J. Teixeira. Regionalização ou municipalização do Brasil? RBEP, Belo Horizonte, n. 63/64, p. 171-183, jul. 1986; jan. 1987.

MACHADO, Hugo de Brito. Curso de direito tributário. 25. ed. rev. atual. e ampl. São Paulo: Malheiros, 2004.

MARTINS, Ives Gandra da Silva. Curso de direito tributário. 9. ed. São Paulo: Saraiva, 2006.

MELO FILHO, Urbano Vitalino de. Perspectiva dos municípios na federação brasileira. In: BASTOS, Evandro de Castro; BORGES JÚNIOR, Odilon (Coords.) Novos rumos da autonomia municipal. São Paulo: Max Limonad, 2000.

PIRES, Maria Coeli Simões. Federalismo brasileiro: a emergência de um redesenho institucional do modelo. Revista Brasileira de Estudos Políticos, Belo Horizonte, n. 106, p. 163-189, 2013.

REZENDE, Fernando. Desafios do federalismo fiscal. Rio de Janeiro: FGV, 2006.

SABBAG, Eduardo. Manual de direito tributário. 5. ed. São Paulo: Saraiva, 2013.

SEGUNDO, Hugo de Brito Machado. Código Tributário Nacional: anotações à Constituição, ao Código Tributário Nacional e às leis complementares 87/1996 e 116/2003. 3. ed. São Paulo: Atlas, 2013.

SILVA, José Afonso da. Curso de direito constitucional positivo. 38. ed. São Paulo: Malheiros, 2015. . O município na constituição de 1988. São Paulo: Revista dos Tribunais, 1989.

SUNDFELD, Carlos Ari Vieira. Regime Constitucional do Município. Revista da Procuradoria Geral do Estado de São Paulo, n. 34, p. 45-70, dez. 1990.

TAVARES, André Ramos. O federalismo social. In: RAMOS, Dircêo Torrecillas (Coord.). $O$ federalista atual: teoria do federalismo. Belo Horizonte: Arraes Editores, 2013.

TAVARES, José. Estudos jurídico-políticos. Lisboa: Universidade Autónoma de Lisboa, 1996.

TÔRRES, João Camillo de Oliveira. O federalismo: formação histórico constitucional. Revista de Ciência Política, Rio de Janeiro, v. 3, n. 2, p. 21-51, abr.jun. 1969.

URBANO VITALINO DE, Melo Filho. Perspectiva dos municípios na federação brasileira. In: BASTOS, Evandro de Castro; BORGES JÚNIOR, Odilon (Coords.) Novos rumos da autonomia municipal. São Paulo: Max Limonad, 2000.

VAMIREH, Chacon. Federalismo aparente e unitarismo permanente no Brasil. RBEP, Belo Horizonte, n. 42, p. 107-126, jan. 1976. 
ZIPPELIUS, Reinhold. Teoria geral do Estado. Tradução: Karin Praefke-Aires Coutinho. Lisboa: Fundação Calouste Gulbenkian, 1997.

Recebido em: 22/10/2017

Aceito em: 10/12/2017 
